Research Article

\title{
Elastoplastic Analysis of Circular Tunnel Based on Drucker-Prager Criterion
}

\author{
Xiongfei Yang, ${ }^{1}$ Hong Yuan $\mathbb{D}^{1},{ }^{1}$ Jiayu $W u,{ }^{1,2,3}$ and Shanqing $\mathrm{Li}(\mathbb{D})^{1}$ \\ ${ }^{1}$ MOE Key Laboratory of Disaster Forecast and Control in Engineering, Institute of Applied Mechanics, Jinan University, \\ Guangzhou 510632, China \\ ${ }^{2}$ Department of Ocean Science and Engineering, Southern University of Science and Technology, Shenzhen 518055, China \\ ${ }^{3}$ School of Engineering, University of Plymouth, Drake Circus, Plymouth PL4 8AA, UK \\ Correspondence should be addressed to Hong Yuan; tyuanhong@jnu.edu.cn
}

Received 25 June 2018; Accepted 28 August 2018; Published 18 September 2018

Academic Editor: Roberto Nascimbene

Copyright (c) 2018 Xiongfei Yang et al. This is an open access article distributed under the Creative Commons Attribution License, which permits unrestricted use, distribution, and reproduction in any medium, provided the original work is properly cited.

\begin{abstract}
Based on the Drucker-Prager yield criterion, the theoretical solution of stratigraphic deformation in tunnel excavation process is deduced by the cavity expansion theory. In view of soil loosening around the tunnel caused by the tunnel excavation process, the internal friction angle of the surrounding soil is not a constant but a function of normal stress. The piecewise linearization of the nonlinear yield function is used to analyze the elastoplastic solution of the cylindrical hole shrinkage. A comparison is conducted with a plastic zone in which the internal friction angle of the soil remains unchanged. It can be concluded that the radial stress, the tangential stress, the radial strain, and the tangential strain around the inner wall calculated from the former are smaller.
\end{abstract}

\section{Introduction}

After subway tunnel excavation, the stress of surrounding soil will be redistributed. When the stress on the surrounding soil exceeds the elastic limit of rock mass and enters into the plastic state, elastoplastic analysis of the surrounding soil must be conducted to determine the stability of the subway tunnel and to provide a basis for the quantitative design of roadway support [1,2]. For deep tunnels, to analyze the surrounding soil stress and displacement generated by tunnel excavation and support, it is not necessary to consider the surface boundary conditions and the surrounding soil can be regarded as an infinite domain and can be solved [3].

There are many examples of prediction of ground displacement caused by tunnel excavation based on the theory of cavity expansion. Mair and Taylor [4] used the Tresca criterion to predict the deformation of soil around the tunnel in clay and compared them with those displacements measured in Green Park and Regent Park in London. Yu and Rowe [5] proposed theoretical and semitheoretical solutions to the expansion of the borehole and the expansion of the sphere in the unloading process during drained and undrained conditions. Pinto and Whittle [6] predicted and expound the deformation of shallowly buried tunnel in the soft soil layer, based on the cavity expansion theory. Mo et al. [7] deduced the theoretical solution of the concentric regions of two different rock soils and also carried out the finite element simulation. For a long time, the elastoplastic analysis of the tunnel has been conducted by adopting the Mohr-Coulomb criterion [4, 8-10] or Hoek-Brown criterion [11-13], based on the fact that the internal friction angle of the surrounding soil is a constant. However, the internal friction angle is a function of normal stress rather than a constant. Kennedy and Lindberg [14] derived small strain solutions based on the segmented Mohr-Coulomb yield surface. Florence and Schwer [15] extended the linear Mohr-Coulomb criterion solution. Recently, Zou et al. $[16,17]$ focused on employing the elastoplastic theories of circular tunnel to solve geotechnical engineering problems and achieved outstanding results.

In this paper, the Drucker-Prager criterion is used as the yield condition, and the plastic analysis of deep-buried circular subway tunnels is performed by using the piecewise 
linearization of nonlinear yield function. A comparison is conducted with a plastic zone in which the internal friction angle of the soil remains unchanged.

\section{Drucker-Prager Yield Criterion}

The Mohr-Coulomb failure criterion can be adopted to describe the yield and failure mechanisms of geomaterials. However, singularity will occur when the directional derivative is on the yield surface at the apex or ridgeline of the hexagonal cone $[18,19]$. In order to overcome the shortcoming of the Mohr-Coulomb failure criterion, Drucker and Prager originally proposed the lower limit of the inscribed Mohr-Coulomb yield surface in 1952 [20], which can be expressed as

$$
\begin{aligned}
& f=\sqrt{J_{2}}-\alpha I_{1}-Y=0, \\
& I_{1}=\sigma_{1}+\sigma_{2}+\sigma_{3}, \\
& J_{2}=\frac{1}{6}\left[\left(\sigma_{1}-\sigma_{2}\right)^{2}+\left(\sigma_{2}-\sigma_{3}\right)^{2}+\left(\sigma_{3}-\sigma_{1}\right)^{2}\right],
\end{aligned}
$$

where $I_{1}$ is the first invariant of the Cauchy stress and $J_{2}$ is the second invariant of the deviator stress tensor. In the formula, the material constants $\alpha$ and $Y$ can be written as

$$
\begin{aligned}
& \alpha=\frac{\sin \varphi}{\sqrt{3} \sqrt{3+\sin \varphi}}, \\
& Y=\frac{\sqrt{3} c \cos \varphi}{\sqrt{3+\sin \varphi}},
\end{aligned}
$$

where $\varphi$ and $c$ are the internal friction angle and the cohesion of soil, respectively.

Assuming the compressive stress as positive and the tensile stress as negative in the calculation, we can obtain the following relation on the basis of the cylindrical cavity expansion theory:

$$
\begin{aligned}
\sigma_{1} & =\sigma_{\theta}, \\
\sigma_{2} & =\sigma_{r}, \\
\sigma_{3} & =0 .
\end{aligned}
$$

Thus, the first invariant of the Cauchy stress and the second invariant of the deviator stress tensor can be simplified as

$$
\begin{aligned}
& I_{1}=\sigma_{\theta}+\sigma_{r}, \\
& J_{2}=\frac{\left(\sigma_{\theta}-\sigma_{r}\right)^{2}}{6} .
\end{aligned}
$$

By substituting Equation (4) into Equation (1), the Drucker-Prager yield criterion can be given by

$$
\left(\sqrt{\frac{1}{6}}-\alpha\right) \sigma_{\theta}-\left(\sqrt{\frac{1}{6}}+\alpha\right) \sigma_{r}=Y .
$$

By letting

$$
\begin{aligned}
& \lambda=\frac{\sqrt{6}+6 \alpha}{\sqrt{6}-6 \alpha}, \\
& \gamma=\frac{6}{\sqrt{6}-6 \alpha},
\end{aligned}
$$

and substituting Equation (6) into Equation (5), $\sigma_{\theta}$ can be transformed as a function of $\sigma_{r}$, which can be written as

$$
\sigma_{\theta}=\gamma Y+\lambda \sigma_{r}
$$

Based on the positional relationship between the Drucker-Prager criterion and the Mohr-Coulomb criterion on the $\pi$ plane (Figure 1), a variety of expressions for the parameters $\alpha$ and $Y$ can be obtained. The parameters $\alpha$ and $Y$ for various yield criteria are listed in Table 1.

\section{Governing Equation}

Before analyzing the elastic and plastic zones of the tunnel, the governing equations should be derived firstly. According to the theory of elasticity, the equilibrium equation of the infinitesimal body around the tunnel can be expressed as

$$
r \frac{d \sigma_{r}}{d r}+\left(\sigma_{r}-\sigma_{\theta}\right)=0
$$

with boundary conditions

$$
\begin{aligned}
& \sigma_{r}=p \text { at } r=a, \\
& \sigma_{r}=p_{0} \text { at } r=\infty .
\end{aligned}
$$

In addition, strain-displacement relations of the soil can be given by

$$
\begin{aligned}
\varepsilon_{r} & =\frac{d u}{d r}, \\
\varepsilon_{\theta} & =\frac{u}{r}, \\
\frac{d \varepsilon_{\theta}}{d r}+\frac{\varepsilon_{\theta}-\varepsilon_{r}}{r} & =0 .
\end{aligned}
$$

After the strain components and displacement are obtained, the stress-strain relation involved in plane strain problem can be given by

$$
\begin{aligned}
& \varepsilon_{r}-\varepsilon_{r}^{p}=\varepsilon_{r}^{e}=\frac{1}{E^{\prime}}\left(\sigma_{r}-\nu^{\prime} \sigma_{\theta}\right), \\
& \varepsilon_{\theta}-\varepsilon_{\theta}^{p}=\varepsilon_{\theta}^{e}=\frac{1}{E^{\prime}}\left(\sigma_{\theta}-\nu^{\prime} \sigma_{r}\right),
\end{aligned}
$$

where

$$
\begin{aligned}
E^{\prime} & =\frac{E}{1-v^{2}}, \\
\nu^{\prime} & =\frac{\nu}{1-\nu} .
\end{aligned}
$$




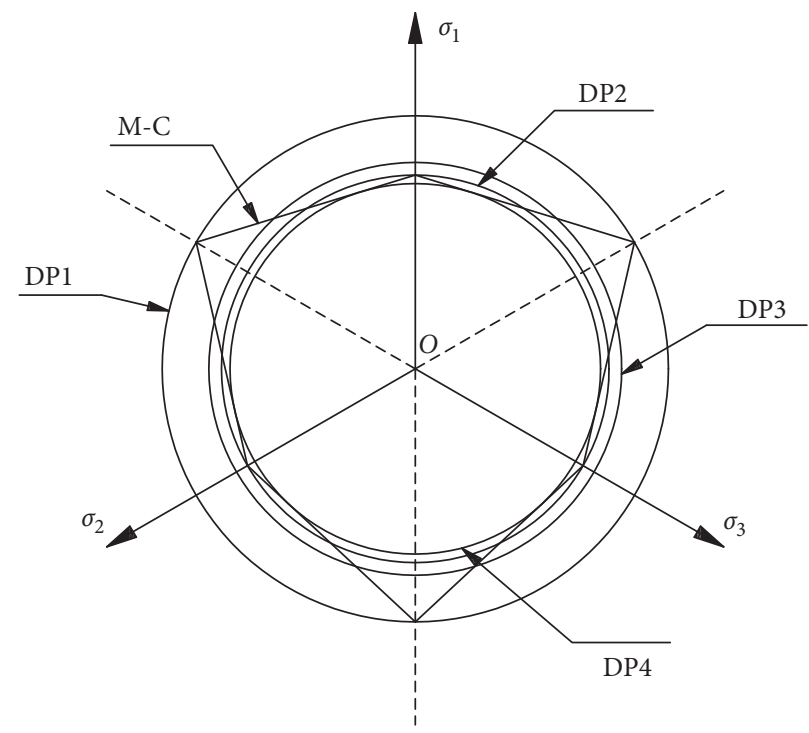

FIgURE 1: Yield surface projected on $\pi$ plane.

TABle 1: The parameters of the common Drucker-Prager yield criterion [21, 22].

\begin{tabular}{lccc}
\hline No. & \multicolumn{1}{c}{ Criterion types } & $\alpha$ & $Y$ \\
\hline DP1 & $\begin{array}{c}\text { The Mohr-Coulomb criterion based with external } \\
\text { corner circumscribed, a circle yield criterion }\end{array}$ & $(2 \sin \varphi) /(\sqrt{3}(3-\sin \varphi))$ & $(6 c \cos \varphi) /(\sqrt{3}(3-\sin \varphi))$ \\
\hline DP2 & $\begin{array}{c}\text { The Mohr-Coulomb criterion based with inner } \\
\text { corner circumscribed, a circle yield criterion }\end{array}$ & $(2 \sin \varphi) /(\sqrt{3}(3+\sin \varphi))$ & $(6 c \cos \varphi) /(\sqrt{3}(3+\sin \varphi))$ \\
\hline DP3 & $\begin{array}{c}\text { The Mohr-Coulomb criterion based with } \\
\text { equivalent area, a circle yield criterion }\end{array}$ & $(2 \sqrt{3} \sin \varphi) /\left(\sqrt{2 \sqrt{3} \pi\left(9-\sin ^{2} \varphi\right)}\right)$ & $(6 \sqrt{3} c \cos \varphi) /\left(\sqrt{2 \sqrt{3} \pi\left(9-\sin { }^{2} \varphi\right)}\right)$ \\
\hline DP4 & $\begin{array}{c}\text { The Mohr-Coulomb criterion based with } \\
\text { matching circles, for plain strain problems with } \\
\text { associated flow rules }\end{array}$ & $(\sin \varphi) /(\sqrt{3} \sqrt{3+\sin \varphi)}$ & $k=(\sqrt{3} c \cos \varphi) /(\sqrt{3+\sin \varphi)}$ \\
\hline
\end{tabular}

\section{Multisection Drucker-Prager Criterion Solution}

In this paper, the elastoplastic closed-form solution of cylindrical hole contraction in the unrestricted DruckerPrager medium is analyzed by piecewise linearization of nonlinear yield function. The pore radius is set as $a$, and the hydrostatic pressure $p_{0}$ is uniformly applied to isotropic soil. Tunnel wall pressure is reduced very slowly, so the power effect can be ignored. As the internal pressure decreases, the inner wall of the hole will fail first. As the pressure of the inner wall of the hole decreases further, the plastic zone will expand outward until it reaches a certain radius $c_{1}$. Eventually, the material in the annular area $a \leq r \leq c_{1}$ is in the plastic state, and the other area $c_{1} \leq r \leq \infty$ is purely elastic.

4.1. Stress Distribution in the Elastic Zone. As the tunnel pressure $p$ decreases from $p_{0}$, the deformation of the soil around the tunnel is purely elastic at the beginning. According to the theory of elasticity, the elastic solutions of stress components can be expressed as

$$
\begin{aligned}
& \sigma_{r}=p_{0}-\left(p_{0}-p\right)\left(\frac{a}{r}\right)^{2}, \\
& \sigma_{\theta}=p_{0}+\left(p_{0}-p\right)\left(\frac{a}{r}\right)^{2} .
\end{aligned}
$$

According to Equations (5) and (6), the yield equation can be obtained as follows

$$
\sigma_{\theta}-\lambda \sigma_{r}=\gamma Y
$$

With the continuous reduction of the pore pressure, the inner wall will trigger an initial yielding when pore pressure reaches the following condition:

$$
p_{y}=\frac{2 p_{0}-\gamma Y}{1+\lambda} \text {. }
$$

4.2. Stress Distribution in the Plastic Zone. When the pore wall reaches the initial yielding, the plastic area will be formed near the inner wall in the region $a \leq r \leq c_{1}$ with decrease of the pressure $p$. As mentioned above, the plastic area is divided into $m$ annular zone, as shown in Figure 2. For different plastic zones, there are different yield conditions 


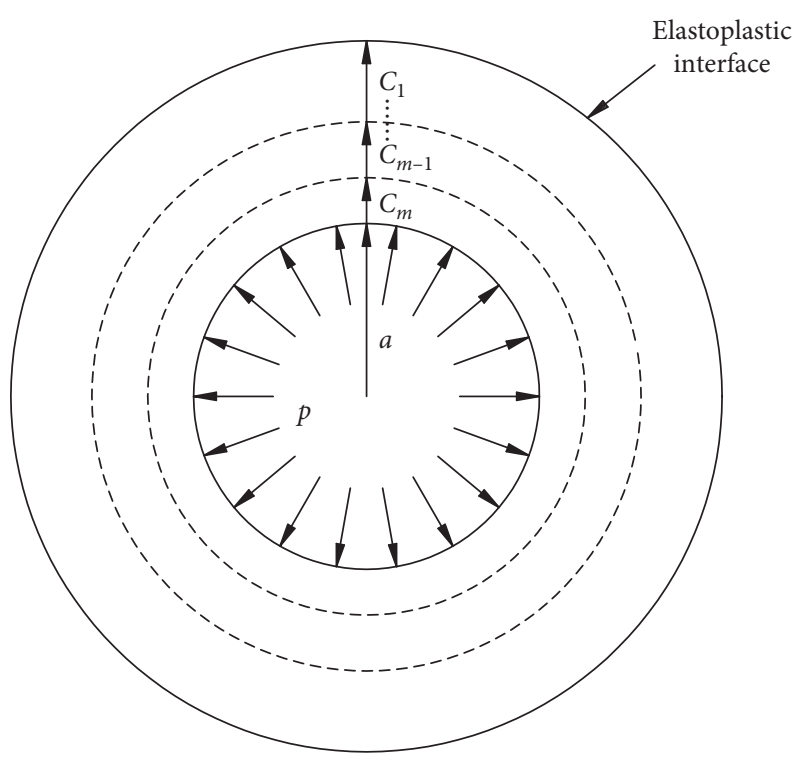

Figure 2: Plastic area is divided into several zones.

represented by different stress functions; hence, each zone can be analyzed separately.

For the plastic zone 1, the yield criterion is given by

$$
f=f_{1}=\sigma_{\theta}-\lambda_{1} \sigma_{r}-\gamma_{1} Y_{1}=0 .
$$

Substituting this yield criterion Equation (19) into the equilibrium equation (Equation (8)), we can obtain the governing equation for the radial stress, which can be expressed as

$$
r \frac{d \sigma_{r}}{d r}+\left(1-\lambda_{1}\right) \sigma_{r}=\gamma_{1} Y_{1}
$$

By solving the Euler equation, the general solution for stress components in the plastic zone 1 can be obtained:

$$
\begin{aligned}
& \sigma_{r}=\frac{\gamma_{1} Y_{1}}{1-\lambda_{1}}+A r^{\lambda_{1}-1}, \\
& \sigma_{\theta}=\frac{\gamma_{1} Y_{1}}{1-\lambda_{1}}+A \lambda_{1} r^{\lambda_{1}-1} .
\end{aligned}
$$

Additionally, the stress components in the outer elastic zone can be expressed as

$$
\begin{aligned}
& \sigma_{r}=p_{0}-B r^{-2}, \\
& \sigma_{\theta}=p_{0}+B r^{-2} .
\end{aligned}
$$

The integral constants $A$ and $B$ can be solved by using the boundary and continuous conditions. Finally, we can obtain

$$
\begin{aligned}
& A=\frac{2\left(1-\lambda_{1}\right) p_{0}-2 \gamma_{1} Y_{1}}{1-\lambda_{1}^{2}} c_{1}^{1-\lambda_{1}}, \\
& B=\frac{\gamma_{1} Y_{1}-\left(1-\lambda_{1}\right) p_{0}}{1+\lambda_{1}} c_{1}^{2} .
\end{aligned}
$$

By substituting Equation (24) into Equation (21), the radial stress at the elastoplastic interface can be obtained

$$
p_{1}=\frac{2 p_{0}-\gamma_{1} Y_{1}}{1+\lambda_{1}}
$$

Similarly, the equilibrium equation for the $i$ th plastic zone can be written as

$$
r \frac{d \sigma_{r}}{d r}+\left(1-\frac{\sqrt{6}+6 \alpha_{i}}{\sqrt{6}-6 \alpha_{i}}\right) \sigma_{r}=\frac{6}{6 \alpha_{i}+\sqrt{6}} Y_{i}
$$

where

$$
\begin{aligned}
& \lambda_{i}=\frac{\sqrt{6}+6 \alpha_{i}}{\sqrt{6}-6 \alpha_{i}}, \\
& \gamma_{i}=\frac{6}{\sqrt{6}-6 \alpha_{i}} .
\end{aligned}
$$

The general solution can be obtained as follows by solving Equation (27).

$$
\sigma_{r}=\frac{\gamma_{i} Y_{i}}{1-\lambda_{i}}+A r^{\lambda_{i}-1}
$$

According to the continuous condition

$$
\left.\sigma_{r}\right|_{r=c_{i}}=p_{i} .
$$

The stress expressions for other plastic zones can be derived. For the zone $i$, stress components can be obtained as

$$
\begin{aligned}
& \sigma_{r}=\frac{\gamma_{i} Y_{i}}{1-\lambda_{i}}+\left(\frac{\gamma_{i} Y_{i}}{\lambda_{i}-1}+p_{i}\right)\left(\frac{r}{c_{i}}\right)^{\lambda_{i}-1}, \\
& \sigma_{\theta}=\frac{\gamma_{i} Y_{i}}{1-\lambda_{i}}+\lambda_{i}\left(\frac{\gamma_{i} Y_{i}}{\lambda_{i}-1}+p_{i}\right)\left(\frac{r}{c_{i}}\right)^{\lambda_{i}-1} .
\end{aligned}
$$

The boundary radius $c_{2}, c_{3}, \ldots, c_{m-1}, c_{m}$ of each region can be determined by the radial stress continuous conditions at the junction of the zone $i-1$ and the zone $i$, which yield

$$
\begin{aligned}
c_{m} & =a\left[\frac{\gamma_{m} Y_{m}+p\left(\lambda_{m}-1\right)}{\gamma_{m} Y_{m}+p_{m}\left(\lambda_{m}-1\right)}\right]^{1 /\left(1-\lambda_{m}\right)}, \\
c_{m-1} & =c_{m}\left[\frac{\gamma_{m-1} Y_{m-1}+p_{m}\left(\lambda_{m-1}-1\right)}{\gamma_{m-1} Y_{m-1}+p_{m-1}\left(\lambda_{m-1}-1\right)}\right]^{1 /\left(1-\lambda_{m-1}\right)}, \\
c_{m-2} & =c_{m-1}\left[\frac{\gamma_{m-2} Y_{m-2}+p_{m-1}\left(\lambda_{m-2}-1\right)}{\gamma_{m-2} Y_{m-2}+p_{m-2}\left(\lambda_{m-2}-1\right)}\right]^{1 /\left(1-\lambda_{m-2}\right)}, \\
c_{1} & =c_{2}\left[\frac{\gamma_{1} Y_{1}+p_{2}\left(\lambda_{1}-1\right)}{\gamma_{1} Y_{1}+p_{1}\left(\lambda_{1}-1\right)}\right]^{1 /\left(1-\lambda_{1}\right)}
\end{aligned}
$$

4.3. Displacement Analysis. This paper mainly discusses the strain and displacement in the elastic and plastic zones. It is convenient to work out the strain expression in the elastic zone by solving the simultaneous Equations (12), (13), (15), and (16). However, the law of plastic flow is required for the calculation strain and displacement in the plastic zone, which will be analyzed by following the associated flow rule. 
Firstly, we calculate the strain and displacement distributions of the plastic zone 1 in the region $c_{2} \leq r \leq c_{1}$, which is close to the outer elastic area. The relationship between two plastic strain components can be obtained by referring to the associated flow rule:

$$
\varepsilon_{r}^{p}+\lambda_{1} \varepsilon_{\theta}^{p}=0 .
$$

Equation (33) can be alternatively written as

$$
\begin{aligned}
& \varepsilon_{r}=\varepsilon_{r}^{e}-\lambda_{1} \varepsilon_{\theta}^{p}, \\
& \varepsilon_{\theta}=\varepsilon_{\theta}^{e}+\varepsilon_{\theta}^{p} .
\end{aligned}
$$

where the tangential plastic strain $\varepsilon_{\theta}^{p}$ is undetermined. When Equations (34) and (35) are substituted into Equation (11), the governing equation for $\varepsilon_{\theta}^{p}$ can be obtained as follows

$$
r \frac{d \varepsilon_{\theta}^{p}}{d r}+\left(1+\lambda_{1}\right) \varepsilon_{\theta}^{p}=g_{1}(r)
$$

where

$$
g_{1}(r)=-\frac{\lambda_{1}^{2}-1}{E^{\prime}}\left[\frac{\gamma_{1} Y_{1}}{\lambda_{1}-1}+p_{1}\right]\left(\frac{r}{c_{1}}\right)^{\gamma_{1}-1} .
$$

The general solution can be derived as follows by solving Equation (36):

$$
\varepsilon_{\theta}^{p}=-\frac{\lambda_{1}^{2}-1}{2 \lambda_{1} E^{\prime}}\left[\frac{\gamma_{1} Y_{1}}{\lambda_{1}-1}+p_{1}\right]\left(\frac{r}{c_{1}}\right)^{\lambda_{1}-1}+B r^{-\lambda_{1}-1},
$$

where the integral constant $B$ is determined by the elastoplastic boundary condition:

$$
\left.\varepsilon_{\theta}^{p}\right|_{r=c_{1}}=0 .
$$

Thus, the integral constant $B$ can be solved:

$$
B=\frac{\lambda_{1}^{2}-1}{2 \lambda_{1} E^{\prime}}\left[\frac{\gamma_{1} Y_{1}}{\lambda_{1}-1}+p_{1}\right] c_{1}^{\lambda_{1}+1} .
$$

Thus, the strain components and displacement in zone 1 are expressed as

$$
\begin{aligned}
\varepsilon_{r}= & \frac{1}{E^{\prime}}\left[\frac{1-v^{\prime}}{1-\lambda_{1}} \gamma_{1} Y_{1}+\left(1-\nu^{\prime} \lambda_{1}+\frac{\lambda_{1}^{2}-1}{2}\right)\left(\frac{\gamma_{1} Y_{1}}{\lambda_{1}-1}+p_{1}\right)\left(\frac{r}{c_{1}}\right)^{\lambda_{1}-1}\right] \\
& -\frac{\lambda_{1}^{2}-1}{2 E^{\prime}}\left(\frac{\gamma_{1} Y_{1}}{\lambda_{1}-1}+p_{1}\right)\left(\frac{c_{1}}{r}\right)^{\lambda_{1}+1}, \\
\varepsilon_{\theta}= & \frac{1}{E^{\prime}}\left[\frac{1-v^{\prime}}{1-\lambda_{1}} \gamma_{1} Y_{1}-\left(\frac{\lambda_{1}^{2}-1}{2 \lambda_{1}}-\lambda_{1}+\nu^{\prime}\right)\left(\frac{\gamma_{1} Y_{1}}{\lambda_{1}-1}+p_{1}\right)\left(\frac{r}{c_{1}}\right)^{\lambda_{1}-1}\right] \\
& +\frac{\lambda_{1}^{2}-1}{2 \lambda_{1} E^{\prime}}\left(\frac{\gamma_{1} Y_{1}}{\lambda_{1}-1}+p_{1}\right)\left(\frac{c_{1}}{r}\right)^{\lambda_{1}+1}, \\
u= & r \varepsilon_{\theta} .
\end{aligned}
$$

Similarly, strain and displacement expressions in other plastic zones can be obtained. The solution of the integral constants can be determined by displacement continuous conditions.

\section{Case Study}

There is a tunnel with the radius $r=a$, the cohesion of the surrounding soil $C=5 \mathrm{MPa}$, the internal friction angle of the surrounding soil $\varphi=30^{\circ}$, and the initial hydrostatic pressure $p_{0}=28.2 \mathrm{MPa}$ acting uniformly on the soil. After tunnel excavation, the pressure of the inner wall of the tunnel will decrease slowly. When the pressure $p$ on the inner wall of the tunnel decreases to $18 \mathrm{MPa}, 12.63 \mathrm{MPa}$, and $3.17 \mathrm{MPa}$, respectively, the distributions of radial stress and tangential stress (dimensionless) around the tunnel are shown in Figure 3.

It can be seen from Figure 3 that the tunnel is in an elastic state when the pore pressure is greater than $12.63 \mathrm{MPa}$, and the radial stress increases with the increase of $r$. In contrast, the tangential stress has opposite tendency. Once the inner wall pressure $p$ decreases to $12.63 \mathrm{MPa}$, plasticity commences around the inner wall of the tunnel, so part of surrounding soil enters the plastic state. The tangential stress in the plastic area increases with the increase of $r$, whereas the tangential stress in the elastic zone decreases with the increase of $r$. In addition, both the radial and tangential stresses far from the tunnel are almost equal to the hydrostatic pressure.

In the plastic area, by substituting Equation (24) into Equation (21), the relationship between the pore pressure $p$ and the plastic area radius $c$ can be given by

$$
p=\frac{\gamma Y}{1-\lambda}+\frac{2(1-\lambda) p_{0}-2 \gamma Y}{1-\lambda^{2}}\left(\frac{c}{a}\right)^{1-\lambda} .
$$

When the tunnel wall pressure $p$ decreases to $3.17 \mathrm{MPa}$, the radius of the plastic area varies with the internal friction angle $\varphi$ and cohesion $C$ of the soil, as shown in Figures 4 and 5, respectively. It can be noted from Figures 4 and 5 that the radius of the plastic area decreases with the increase of the inner friction angle $\varphi$ and cohesion $C$ of the surrounding soil. It indicates that it is essential to use varying inner friction angle $\varphi$ and cohesion $C$ of the surrounding soil to characterize the mechanical behavior of tunnel excavation.

Notably, it is an efficient way to calculate the elastoplastic solution of tunnel excavation by using piecewise linear yield function to represent the nonlinear yield criterion. Based on the influence of the normal stress on the internal friction angle of the soil, we divided the plastic area into seven zones. The yield criterion for each zone with various internal friction angles can be expressed as 


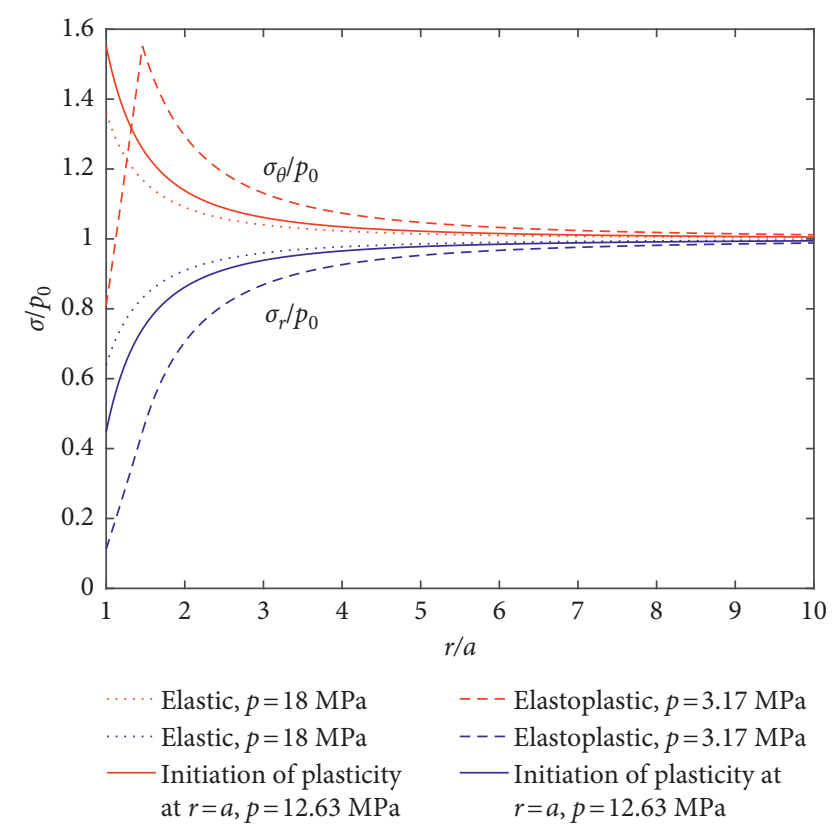

FIGURE 3: Variation of radial stress and tangential stress of soil around the tunnel.

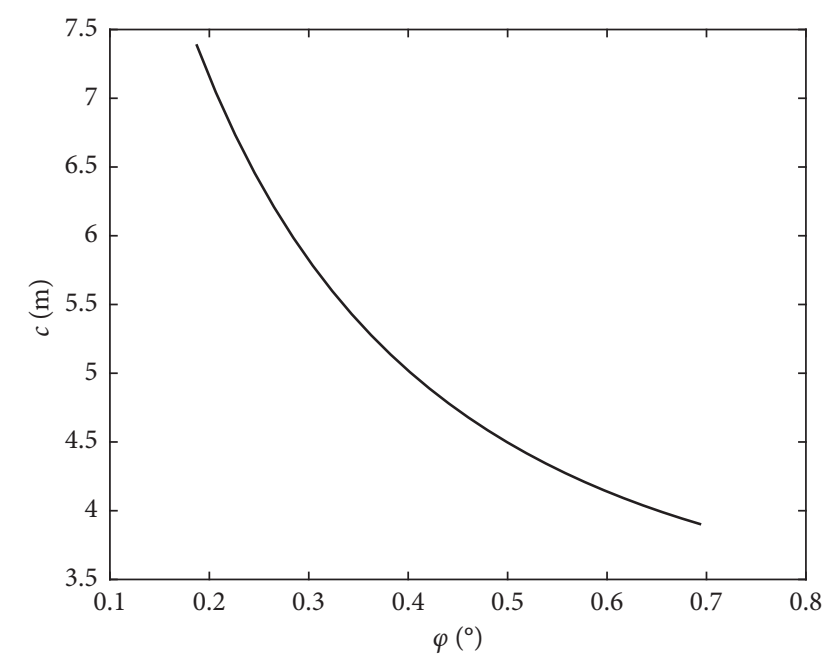

FIGURE 4: Relationship between the radius of plastic zone and internal friction angle $\varphi$.

$$
\left.\begin{array}{l}
\varphi_{1}=30^{\circ}, \quad f_{1}=0 \text { when } 0.9 p_{1} \leq \sigma_{r}<p_{1} \\
\varphi_{2}=28.5^{\circ}, f_{2}=0 \text { when } 0.8 p_{1} \leq \sigma_{r}<0.9 p_{1} \\
\varphi_{3}=27^{\circ}, \quad f_{3}=0 \text { when } 0.7 p_{1} \leq \sigma_{r}<0.8 p_{1} \\
\varphi_{4}=25.5^{\circ}, f_{4}=0 \text { when } 0.6 p_{1} \leq \sigma_{r}<0.7 p_{1} \\
\varphi_{5}=24^{\circ}, \quad f_{5}=0 \text { when } 0.5 p_{1} \leq \sigma_{r}<0.6 p_{1} \\
\varphi_{6}=22.5^{\circ}, f_{6}=0 \text { when } 0.4 p_{1} \leq \sigma_{r}<0.5 p_{1} \\
\varphi_{7}=21^{\circ}, \quad f_{7}=0 \text { when } p \leq \sigma_{r}<0.4 p_{1}
\end{array}\right\} .
$$

Comparison of stress components between one plastic area with internal friction angle $\varphi=30^{\circ}$ and seven separated plastic zones with various internal friction angles is shown in

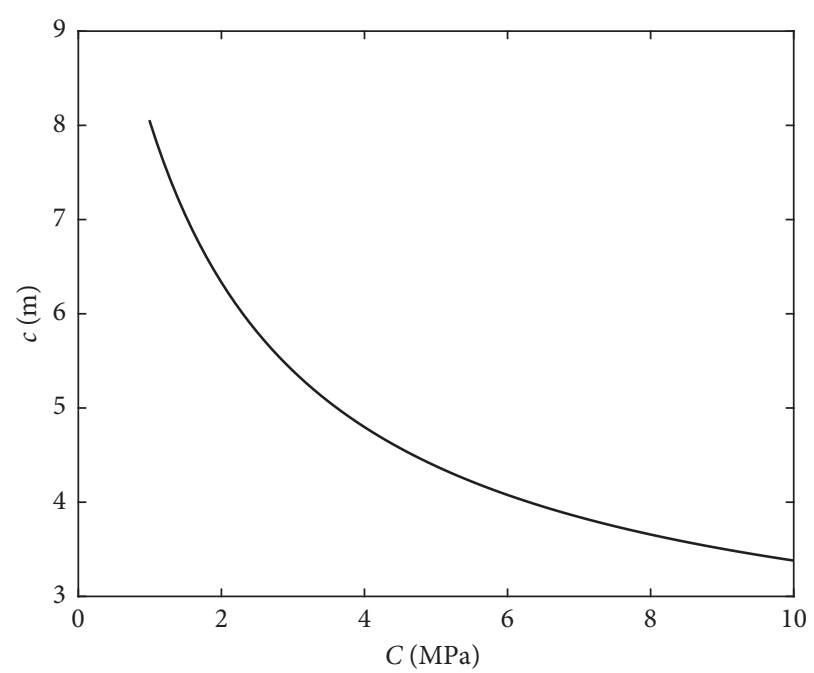

FIgURE 5: Relationship between the radius of plastic zone and cohesion $C$.

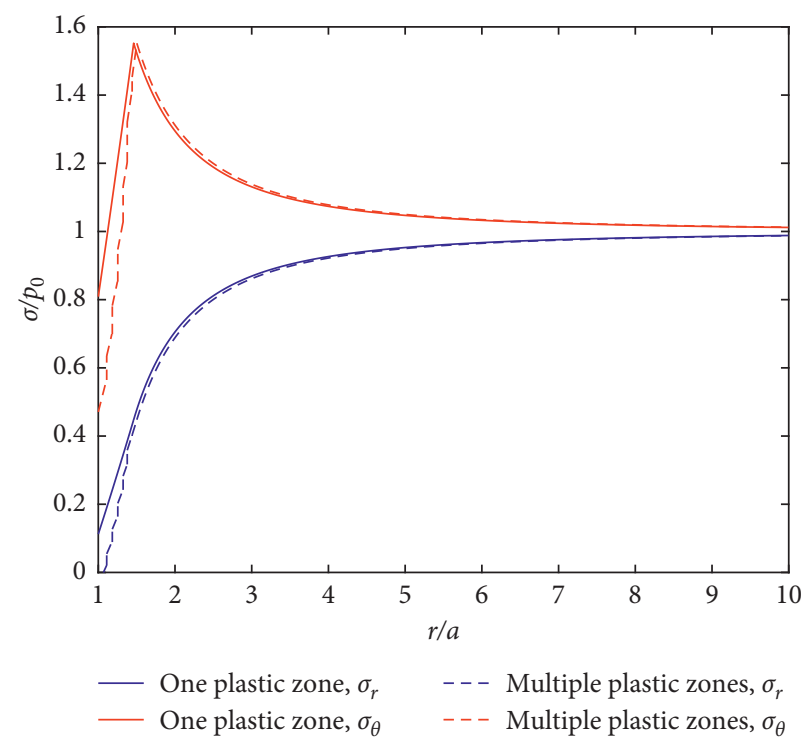

FIgURE 6: Stress distributions divided into a plastic zone and multiple plastic zones.

Figure 6, and the corresponding strain components' comparison is shown in Figure 7.

In practical engineering, the closer the distance from the tunnel is, the looser the soil becomes during tunnel excavation and the smaller the internal friction angle becomes. Figures 6 and 7 depict that the radius of the plastic area increases when the plastic area is divided into seven zones. The stress and strain components around the inner wall of the tunnel decrease. However, the values of stress and strain components in the elastic area are very close.

To have a better understanding of the stress and strain distributions around the tunnel, finite element software ANSYS is used for numerical simulation [23]. Twodimensional element PLANE42 is used to simulate surrounding soil. Under symmetrical conditions, a-quarter 


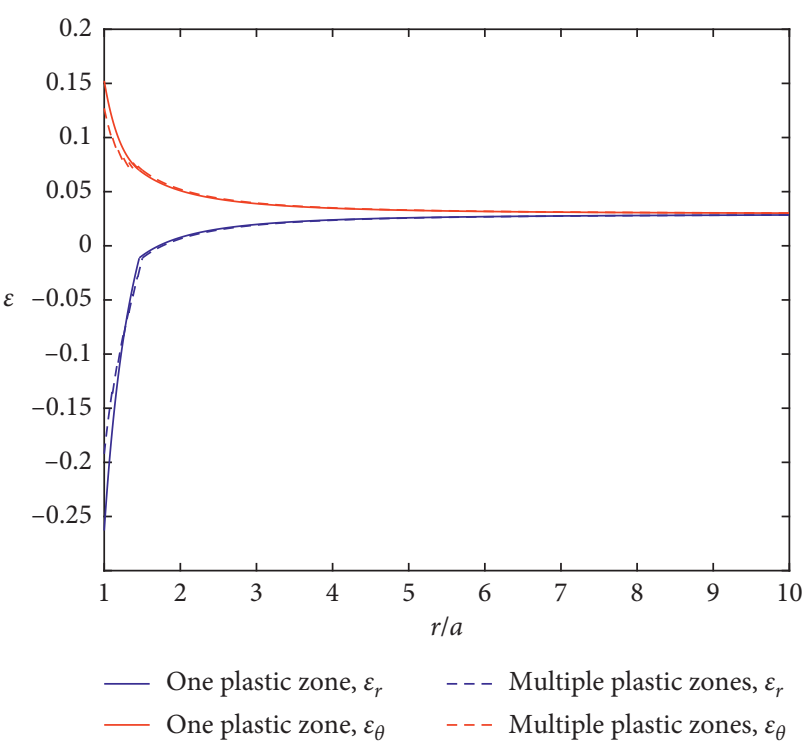

Figure 7: Strain distributions divided into a plastic zone and multiple plastic zones.

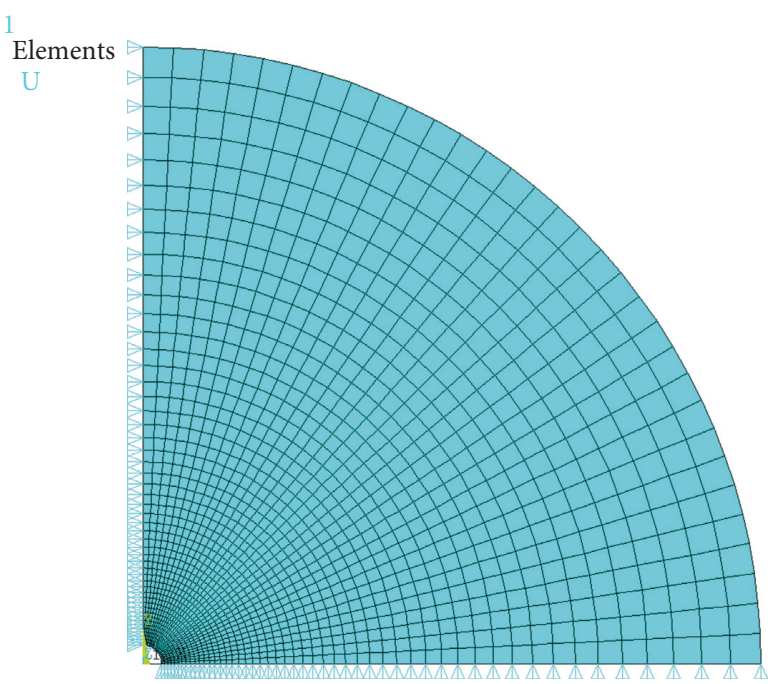

FIGURE 8: Finite element model of a-quarter structure.

mode with 1,600 elements and 1,683 nodes is constructed, as depicted in Figure 8. The radius of the surrounding soil is $100 \mathrm{~m}$, and the radius $a$ of the tunnel is equal to $3 \mathrm{~m}$. Comparison between finite element results and analytical results is illustrated in Figures 9 and 10, respectively.

According to Figures 9 and 10, we consider tunnel excavation as the two-dimensional plane strain problem in the theoretical derivation, without considering the influence of strain $\varepsilon_{z}$ along the tunnels. This leads to a larger analytical solution of tangential stress $\sigma_{\theta}$ in plastic area and a smaller radius in plastic area. Notably, by using the associated flow rule to analyze the plastic strain, the analytical solution of $\varepsilon_{r}$ near the inner wall of the tunnel becomes larger. The good agreement in elastic area between finite element results and theoretical results validates the model developed in the current study. Furthermore, our model results are in good

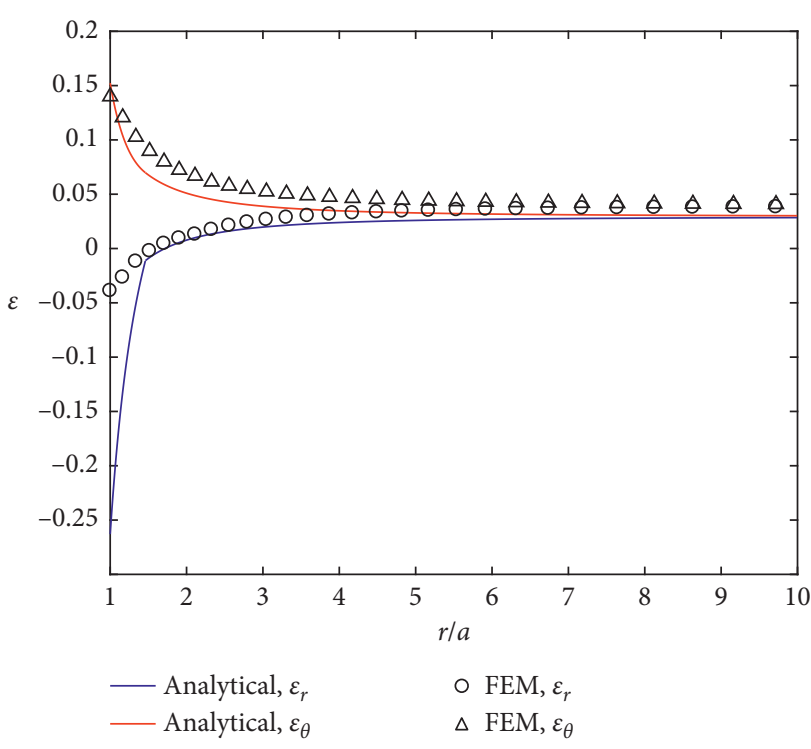

FIgURE 9: Comparison of strain distribution between analytical solution and finite element solution.

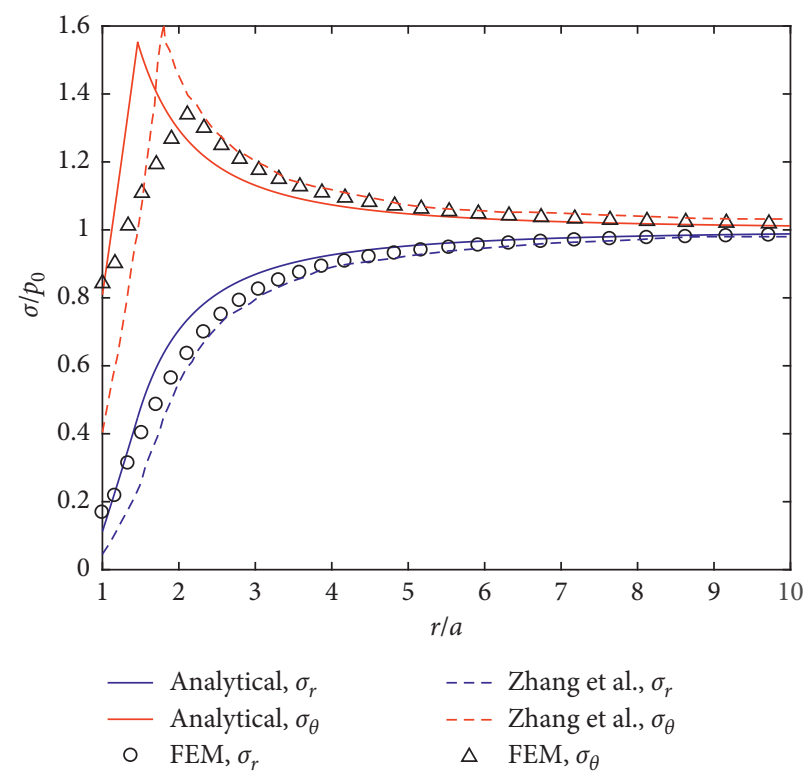

Figure 10: Comparison of stress distribution between analytical solution and finite element solution.

agreement with the numerical results proposed by Zhang et al. [24].

\section{Conclusions}

Taking into account loosening of the soil around the tunnel caused by the tunnel excavation, the internal friction angle of rock and soil is not a constant but a function of normal stress. The piecewise linearization of nonlinear yield function was used to analyze the elastoplastic solution of shrinkage of cylindrical pores based on the Drucker-Prager yield criterion. A comparison is conducted with a plastic zone in which the internal friction angle of the soil remains 
unchanged. Based on this study, the following conclusions can be drawn:

(1) The tunnel excavation process leads to decrease of the pressure on the inner wall of the tunnel and increase of the radius of the plastic area. The radius of the plastic area is related to the internal friction angle and cohesion of the soil in the tunnel.

(2) The radius of the plastic area decreases with increasing of the inner friction angle and cohesion of the surrounding soil.

(3) Compared with only one plastic zone (internal friction angle $\varphi=30^{\circ}$ ), when the plastic area is divided into seven zones, the radius of the plastic area increases and the stress and strain components around the inner wall of tunnel decrease, but the distributions of stress and strain in the elastic area are very close.

\section{Data Availability}

The data used to support the findings of this study are included within the article.

\section{Conflicts of Interest}

The authors declare that they have no conflicts of interest.

\section{Acknowledgments}

The authors gratefully acknowledge the financial support provided by the National Natural Science Foundation of China (nos. 11032005 and 11402099), the Science and Technology Scheme of Guangdong Province (no. 2012A030200003), the Science and Technology Scheme of Guangzhou City (no. 1563000451), and the Fundamental Research Funds for the Central Universities of China (no. 17817004).

\section{References}

[1] M. Hajiazizi and P. Bastan, "The elastoplastic analysis of a tunnel using the EFG method: a comparison of the EFGM with FEM and FDM," Applied Mathematics \& Computation, vol. 234, pp. 82-113, 2014.

[2] C. H. Tan, "Difference solution of passive bolts reinforcement around a circular opening in elastoplastic rock mass," International Journal of Rock Mechanics \& Mining Sciences, vol. 81, pp. 28-38, 2016.

[3] Y. Xiang, General Theory of Tunnel Mechanics, Science Press, Beijing, China, 2014, in Chinese.

[4] R. J. Mair and R. N. Taylor, "Prediction of clay behavior around tunnels using plasticity solutions. Predictive Soil Mechanics," in Proceedings of the Wroth Memorial Symposium, pp. 27-29, Oxford, UK, July 1992.

[5] H. S. Yu and R. K. Rowe, "Plasticity solutions for soil behaviour around contracting cavities and tunnels," International Journal for Numerical \& Analytical Methods in Geomechanics, vol. 23, no. 12, pp. 1245-1279, 2015.

[6] F. Pinto and A. J. Whittle, "Ground movements due to shallow tunnels in soft ground. I: analytical solutions," Journal of Geotechnical \& Geoenvironmental Engineering, vol. 140, no. 4, article 04013040, 2014.
[7] P. Mo, A. M. Marshall, and H. Yu, "Elastic-plastic solutions for expanding cavities embedded in two different cohesive-frictional materials," International Journal for Numerical \& Analytical Methods in Geomechanics, vol. 38, no. 9, pp. 961-977, 2014.

[8] Y. Xiang and S. Feng, “Theoretical prediction of the potential plastic zone of shallow tunneling in vicinity of pile foundation in soils," Tunnelling and Underground Space Technology, vol. 38, pp. 115-121, 2013.

[9] H. S. Yu and G. T. Houlsby, "A large strain analytical solution for cavity contraction in dilatant soils," International Journal for Numerical \& Analytical Methods in Geomechanics, vol. 19, no. 11, pp. 793-811, 2010.

[10] Z. Qiang, S. Wang, and G. E. Xiurun, "Elastoplastic analysis of circular openings in strain-softening rock masses," Chinese Journal of Rock Mechanics \& Engineering, vol. 29, pp. 10311035, 2010.

[11] E. T. Brown, J. W. Bray, B. Ladanyi, and E. Hoek, "Ground response curves for rock tunnels," Journal of Geotechnical Engineering, vol. 109, no. 1, pp. 15-39, 1983.

[12] C. Carranza-Torres, B. Rysdahl, and M. Kasim, "On the elastic analysis of a circular lined tunnel considering the delayed installation of the support," International Journal of Rock Mechanics \& Mining Sciences, vol. 61, pp. 57-85, 2013.

[13] E. Hoek and E. T. Brown, Underground Excavations in Rock, Institute of Mining and Metallurgy, London, UK, 1980.

[14] T. C. Kennedy and H. E. Lindberg, "Tunnel closure for nonlinear Mohr-Coulomb functions," Journal of the Engineering Mechanics Division, vol. 104, pp. 1313-1326, 1978.

[15] A. L. Florence and L. E. Schwer, "Axisymmetric compression of a Mohr-Coulomb medium around a circular hole," International Journal for Numerical \& Analytical Methods in Geomechanics, vol. 2, pp. 367-379, 1978.

[16] J. F. Zou, K. F. Chen, and Q. J. Pan, "An improved numerical approach in surrounding rock incorporating rockbolt effectiveness and seepage force," Acta Geotechnica, vol. 13, no. 3, pp. 707-727, 2018.

[17] J. F. Zou and Z. H. Qian, "Face stability analysis of tunnel excavated below groundwater considering coupled flow-deformation," International Journal of Geomechanics, vol. 18, no. 8, article 04018089, 2018.

[18] P. Papanastasiou and D. Durban, "Singular crack-tip plastic fields in tresca and Mohr-Coulomb solids," International Journal of Solids \& Structures, vol. 136-137, pp. 250-258, 2018.

[19] D. J. Robert, "A modified Mohr-Coulomb model to simulate the behavior of pipelines in unsaturated soils," Computers and Geotechnics, vol. 91, pp. 146-160, 2017.

[20] A. S. Khan and S. Huang, Continuum Theory of Plasticity, John Wiley \& Sons, Hoboken, NJ, USA, 1995.

[21] Y. Zheng, X. Tang, S. Zhao, C. Deng, and W. Lei, "Strength reduction and step-loading finite element approaches in geotechnical engineering," Journal of Rock Mechanics \& Geotechnical Engineering, vol. 1, pp. 21-30, 2009.

[22] X. Yi, P. P. Valkó, and J. E. Russell, "Effect of rock strength criterion on the predicted onset of sand production," International Journal of Geomechanics, vol. 5, pp. 66-73, 2005.

[23] K. M. Thompson and M. J. Thompson, ANSYS Mechanical APDL for Finite Element Analysis, Butterworth-Heinemann, Woburn, MA, USA, 2017.

[24] X. Zhang, G. Zhao, and X. Meng, "Elastoplastic analysis of surrounding rock on circular roadway based on DruckerPrager yield criterion," Journal of China Coal Society, vol. 38, pp. 30-37, 2013. 


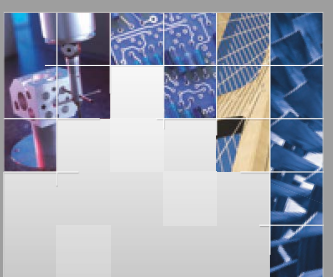

\section{Enfincering}
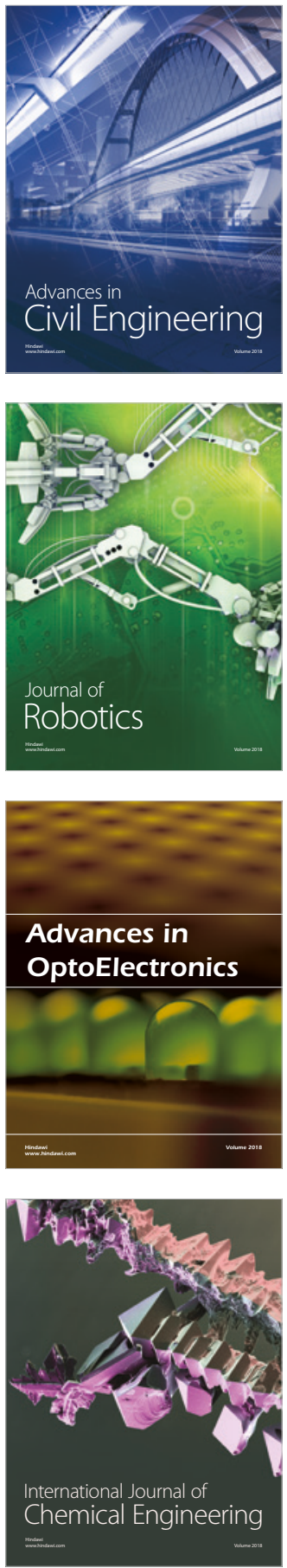

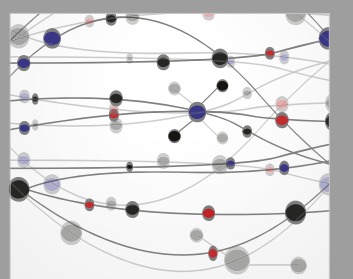

\section{Rotating \\ Machinery}

The Scientific World Journal

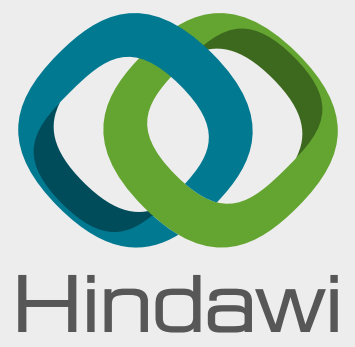

Submit your manuscripts at

www.hindawi.com
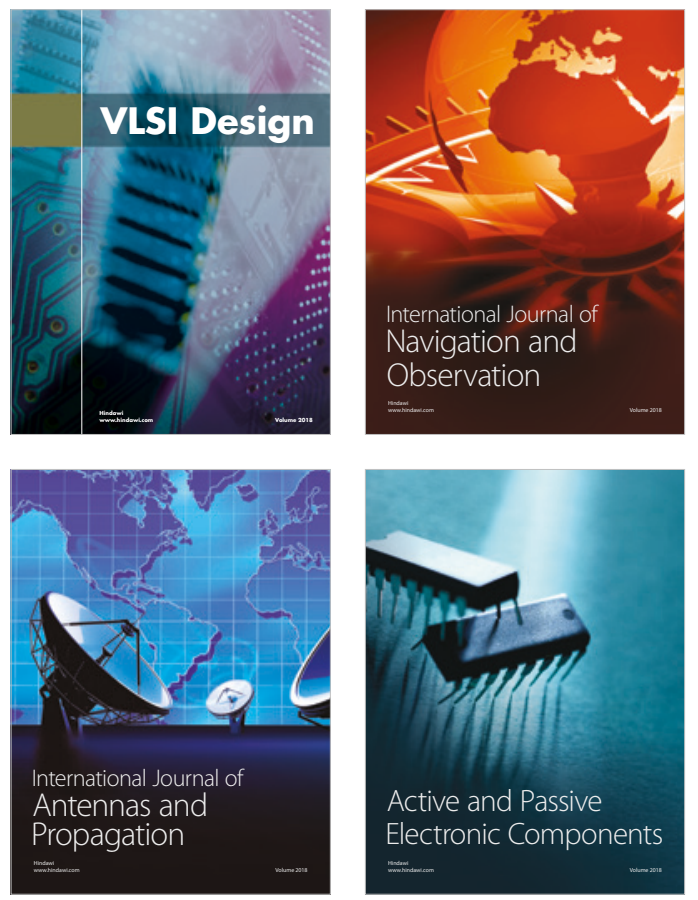
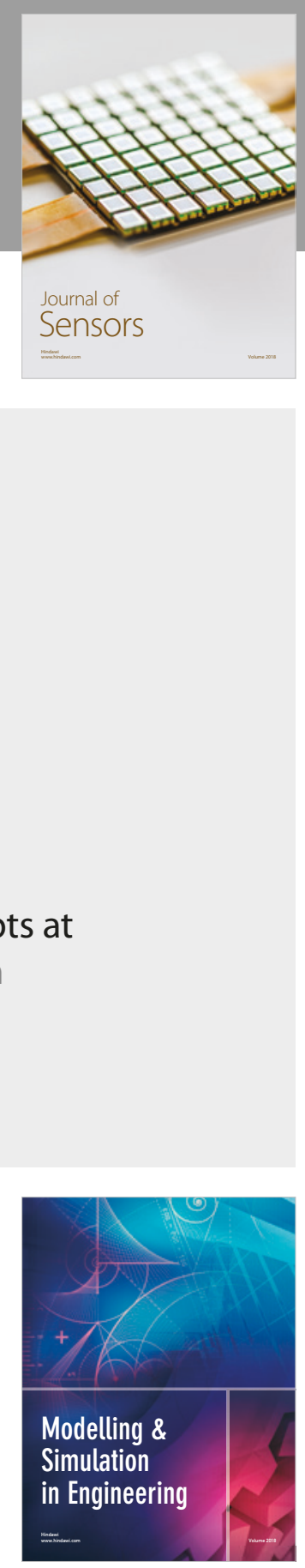

\section{Advances \\ Multimedia}
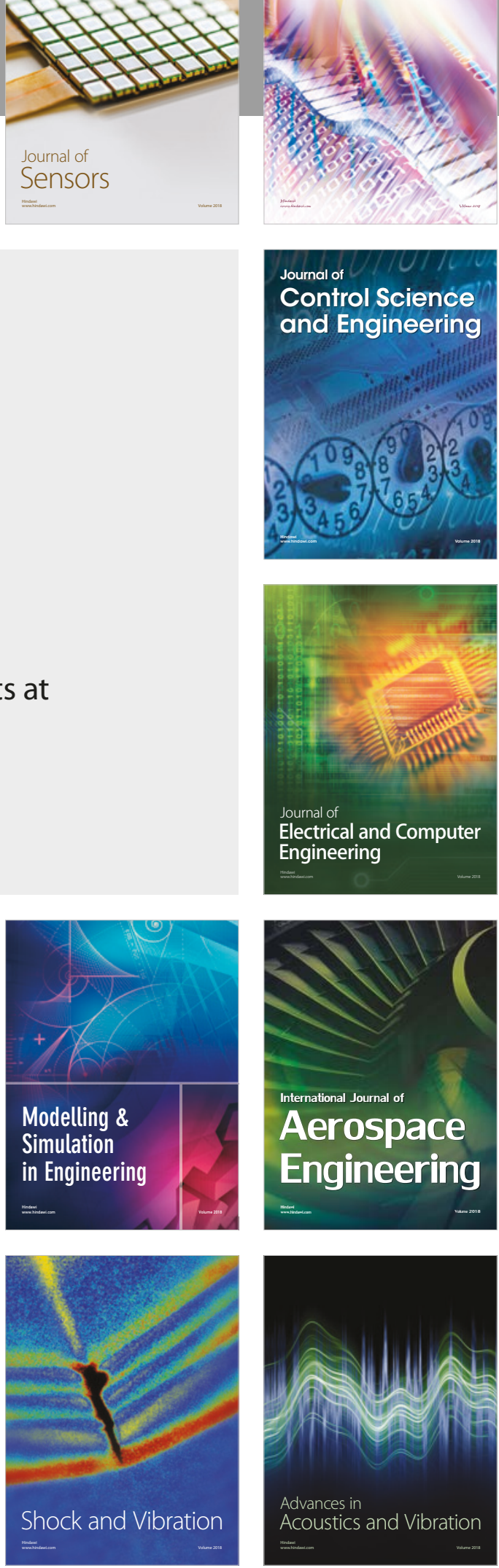